\section{Patient with giant Becker's nevus and epidermal nevus}

\author{
George Issa, Travis W. Blalock, \\ Jack L. Lesher \\ Medical College of Georgia, Division \\ of Dermatology, Augusta, GA, USA
}

\begin{abstract}
Becker's nevus is a cutaneous hamartoma that may be present at birth, but more commonly is noticed during puberty. It classically manifests unilaterally on the shoulder and upper trunk as a tan to brown patch or thin plaque. "It typically has an irregular margin,

breaks up into islands at the periphery, and has an average size of 125 square centimeters. Numerous skin, soft-tissue, and bony anom-
\end{abstract}

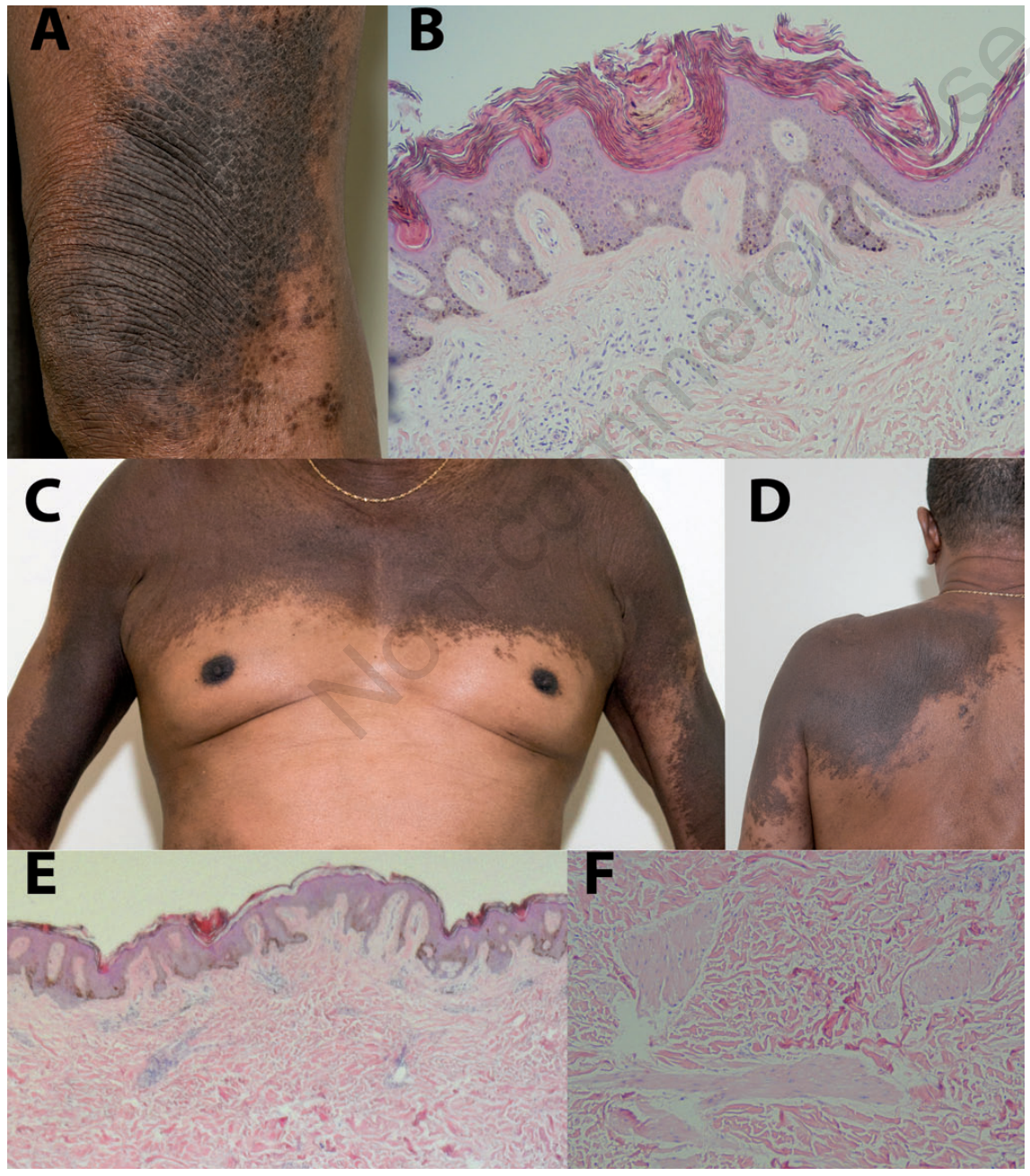

Figure 1. Hyperpigmented scaly plaque on left lower extremity consistent with epidermal nevus (A). Biopsy of (A) showing increased basilar pigmentation, acanthosis, and hyperkeratosis $(B, H \& E$ 5X). Large hyperpigmented patch with irregular borders and satellite macules $(C \& D)$ consistent with Becker's nevus. Increased basilar pigmentation $(E, H \& E$ $10 \mathrm{X}$ ) and smooth muscle proliferation (F, H\&E 20X) in biopsies from lesion (C). alies have been reported in association with Becker's nevus. We describe a patient with Becker's nevus of considerable size who has a

\section{Case Report}

A 70 year old black male presents with a lesion on his left lower extremity and one on his trunk that he has had since adolescence. The lesion on his lower extremity is a hyperpigmented scaly plaque extending along his left lateral thigh, knee, and leg (Figure 1A), biopsy of which demonstrates hyperkeratosis with acanthosis and increased pigmentation at the basal layer, consistent with an epidermal nevus (Figure 1B). The lesion on his trunk is a hyperpigmented patch with irregular borders and satellite macules extending bilaterally to his medial arms across his left shoulder and concurrent epidermal nevus.
Correspondence: Travis W. Blalock, MD, Medica College of Georgia, Division of Dermatology, 1004 Chafee Ave., Augusta, GA 30904, USA.

Tel. +1.706.721.6231 - Fax: +1.706.721.6220

E-mail: tblalock@mcg.edu

Key words: epidermal nevus, Becker's nevus, epidermal nevus syndrome.

Contributions: all authors have contributed significantly and are in agreement with the content of the manuscript.

Funding/Support: there were no funding sponsors in the collection, analysis, and interpretation of data; or in the preparation, review, or approval of the manuscript.

Received for publication: 9 August 2011.

Accepted for publication: 9 August 2011.

This work is licensed under a Creative Commons Attribution NonCommercial 3.0 License (CC BYNC 3.0).

(C) Copyright G. Issa et al., 2011

Licensee PAGEPress, Italy

Dermatology Reports 2011; 3:e23

doi:10.4081/dr.2011.e23

onto his lower neck (Figure 1C/1D). Biopsy demonstrates acanthosis, hyperkeratosis with regular elongation of rete ridges, increased basal layer pigmentation with a normal number of melanocytes, and an increase in smooth muscle bundles in the dermis (Figure 1E/1F), consistent with a Becker's nevus. ${ }^{1,2}$ The patient is otherwise healthy with no clinically significant medical history, developmental anomalies, or family history of similar lesions.

\section{Discussion}

The pathogenesis of Becker's nevus remains uncertain. There is a male to female ratio of $5: 1 .^{1}$ This, along with the increased number of terminal hairs seen within many lesions, and reports of acne vulgaris confined to Becker's nevi, has raised the suspicion of androgenic stimulation as an underlying factor. Hypertrichosis is present in approximately one-half of cases and there is often an associated smooth muscle hamartoma. ${ }^{1}$

Epidermal nevi are congenital hamartomas that arise from pluripotential germinative cells of the basal layer of the embryonic epidermis. ${ }^{3}$ They appear as patches, plaques, or nodules that may be bilateral and most commonly affect the face, trunk, and proximal extremities. ${ }^{4,5} \mathrm{An}$ estimated one third of affected individuals have involvement of other organs, which is called epidermal nevus syndrome. ${ }^{5}$ This sporadic neurocutaneous linkage of congenital ec- 
todermal defects can affect the skin, brain, eyes, and/or skeleton. ${ }^{5}$ As some authors regard Becker's nevi as a subclass of epidermal nevi, patients with Becker's nevi should be examined for associated soft tissue, neurologic, ophthalmologic, and bony abnormalities.

The Becker's nevus in our patient is remarkable due to its large size and co-existence with an epidermal nevus. A study of French men estimated the prevalence of Becker's nevi to be approximately $0.5 \%$, while epidermal nevi have an incidence of approximately $0.1 \%$ of newborns. ${ }^{1,6}$ There is considerable debate in the literature regarding these two entities, some regarding both lesions as cutaneous hamartomas while others consider them each to be versions of epidermal nevi. ${ }^{6}$ Regardless of the classification, the presence of both lesions in a single patient is very unusual, and to our knowledge, simultaneous expression of these two lesions has not been previously reported.

\section{References}

1. Grande Sarpa H, Harris R, Hansen CD, Callis Duffin KP, Florell SR, Hadley ML. Androgen receptor expression patterns in Becker's nevi: an immunohistochemical study. J Am Acad Dermatol 2008;59:834-8.

2. Person, JR, Longcope, C. Becker's nevus: an androgen-mediated hyperplasia with increased androgen receptors. J Am Acad Dermatol 1984;10:235-238.

3. Copeman PW, Jones EW. Pigmented hairy epidermal nevus (Becker). Arch Dermatol Sep 1965;92:249-51.

4. Rogers M, McCrossin I, Commens C. Epidermal nevi and the epidermal nevus syndrome. A review of 131 cases. J Am Acad Dermatol Mar 1989;20:476-88.

5. Vidaurri-de la Cruz H, Tamayo-Sanchez L, Duran-McKinster C, de la Luz Orozco-Covarrubias M, Ruiz-Maldonado R. Epidermal nevus syndromes: clinical findings in 35 patients. Pediatr Dermatol 2004;21:432-9.

6. Kose 0, Caliskan C, Kurumlu, Z. Three different epidermal naevi with no organ involvement: Sebaceous naevus, naevus comedonicus and Becker's nevus. Acta Derm Venereol 2008;88:67-9. 